\title{
Semiotsko-semantična narava glasbe
}

\section{The Semiotic-Semantic Nature of Music}

Ključne besede: semiotika glasbe, semantika glasbe, referencialnost glasbe

IZVLEČEK

Namen članka je razrešitev metodološko-epistemološkega problema prvenstva semiotike oz. semantike v glasbi, ki je razrešeno $s$ pomočjo razkritja dvojne narave glasbene referencialnosti (zunanje in notranje nanašanje) oz. kulturne, semitsko-semantične pogojenosti povednosti glasbe.
Keywords: the semiotics of music, the semantics of music, the referentiality of music

ABSTRACT

The purpose of the article is to solve the methodological-epistemological problem of the key position of semiotics and semantics in music. This is solved with the aid of the discovery of the dual nature of musical referentiality (internal and external references) and of the cultural, semiotic-semantic conditionality of the musical narrative.

Ob vprašanjih, $k a j$ - če sploh - in $k a k o$ pomeni glasba, trčimo najprej na metodološko-epistemološki problem, katera izmed izbranih perspektiv - glasbeno-semiološka, glasbeno-semiotska ali glasbeno-semantična - je za raziskovanja povednosti glasbe najprimernejša. Zdi se, da si posamezni znanstveniki in njihove tradicije že v tem pogledu stojijo močno vsaksebi, hkrati pa nam more nekaj malega o nenavadni naravi glasbene povednosti povedati prav takšna raznolikost.

Tako stopa Jean-Jacques Nattiez v značilnem strukturalističnem duhu na stran glasbene semiologije, ki naj bi bila zmožna »opazovati« vse nivoje »totalnega glasbenega fakta«. ${ }^{1}$ Seveda pa je potrebno Nattiezov izraz »semiologija« razumeti v povezavi z lingvističnim izročilom F. de Saussura, zaradi česar lahko semiologijo izenačimo s semiotiko v ne-frankofonskih kulturah. Tako se v osnovnih znanstvenih postavkah Nattiezova semiologija ne razlikuje bistveno od glasbene semiotike, ki jo zagovarja V. Kofi Agawu. ${ }^{2}$ Agawuja zanima sistem funkcioniranja glasbenih znakov, medtem ko je raziskovanje referenčnih vezi zanj drugotnega pomena. Prav zato izpostavlja prvenstvo glasbene semiotike, ki se ukvarja z raziskovanjem znakov samih, in zavrača glasbeno semantiko, ki svojo raziskovalno ost namenja predvsem odkrivanju pomenov.

\footnotetext{
Prim. Jean-Jacques Nattiez. Fondements d'une Sémiologie de la Musique. Paris: Union Générale d'Editions 1975.

2 V. Kofi Agawu. Playing with Signs. A Semiotic Interpretation of Classic Music. Princetown: Princetown University Press 1991, 5.
} 
Podobno je kritičen do glasbene semantike tudi Peter Faltin, ki kot vodilno disciplino pri razkrivanju glasbenih pomenov spet izpostavlja glasbeno semiotiko. Slednja naj ne bi bila zgolj veda o znakih samih, torej znanost, katere naloge so povezane z urejanjem, tipologiziranjem in prepoznavanjem znakov. Semiotika ni le taksonomija znakov, temveč je po Faltinu del spoznavne teorije ali celo fundamentalne filozofije. ${ }^{3}$ Pomen znaka, s katerim naj bi se prvenstveno ukvarjala semantika, je po Faltinu pravzaprav težko izolirati od znaka samega; pomen je druga stran znaka, ki je otipljiva materialnost pomena in tako je lahko v določenih primerih (predvsem pri t.i. estetskih znakih) znak celo identičen s pomenom. ${ }^{4}$ Ker znaki brez pomenov sploh ne obstajajo in ker je le-ta njihov integralni del, se zdi Faltinu nesmiselno ločevati semiotiko od pomenov.

Faltinovo oženje problemskega območja še bolj radikalno nadaljujeta Tibor Kneif in Reinhard Schneider. Kneif tako dvomi tudi o smiselnosti obstoja glasbene semiotike, ne le semantike. ${ }^{5}$ Da bi namreč glasbo lahko preučevali kot semiotski sistem, bi morala le-ta izkazovati znakovne kvalitete, Kneif pa je prepričan, da imajo redki »pravi« glasbeni znaki le periferni pomen. Podobno skeptičen je tudi Schneider, ki zaključuje, da je semiotika gotovo znanost, a ne znanost o glasbi. ${ }^{6}$ Do takega negativnega zaključka pride prek spoznanja, da so vse semiotske teorije, ki se ukvarjajo z glasbo, izrasle pravzaprav iz lingvističnih temeljev in zato odpovedo ob drugem predmetu: semiotika naj bi bila torej prvenstveno metoda za raziskovanje jezika, ne glasbe.

Povsem drugačno pa je izhodišče Vladimirja Karbusickega, ki stopa na stran glasbene semantike. ${ }^{7}$ Karbusicky ne raziskuje delovanja glasbe kot urejenega semiotičnega sistema, saj je močno skeptičen do možnosti, da bi glasbo obravnavali kot kompleksen sistem znakov. V središču zanimanja Karbusickega se tako postavlja pomen, ki ga glasba lahko pridobi v procesu recepcije $\mathrm{z}$ aktom »sekundarne semantizacije».

Raziskovalci se torej v svojih izhodiščih vsaj navidez postavljajo povsem na različne bregove - J.-J. Nattiez je zapisan glasbeni semiologiji, V. K. Agawu in P. Faltin glasbeni semiotiki, V. Karbusicky glasbeni semantiki, medtem ko sta T. Kneif in R. Schneider močno zadržana tako do glasbene semiotike (ali semiologije) kot tudi glasbene semantike. Pri tem je najbolj simptomatično, da Karbusicky in Kneif kljub močno različnim izhodiščem v bran svoji teoriji izpostavljata praktično identičen argument. Tako Karbusicki prvenstvo glasbene semantike utemeljuje zaradi odsotnosti znakovnosti glasbe, ista ugotovitev pa Kneifa vodi k tezi o neobstoju tako glasbene semiotike kot semantike.

Prav zaradi podobnih aporij se zdi nesmiselno vztrajanje pri katerikoli izmed skrajnih pozicij, ki bi ju bilo mogoče izluščiti iz zgoraj predstavljenih izhodišč, in sicer da cela glasba izkazuje znakovne kvalitete ali pa, da takih kvalitet glasba sploh nima in je zaradi

\footnotetext{
Peter Faltin. Bedeutung ästhetischer Zeichen. Musik und Sprache, ur. Christa Nauck-Börner. Aachen: Rader Verlag 1985, 22.

Peter Faltin. 'Musikalische Bedeutung. Grenzen und Möglichkeiten einer semiotischen Ästhetik'. V:International Review of the Aesthetics and Sociology of Music 9/1 (1978), 9.

5 Tibor Kneif. 'Anleitung zum Nichtverstehen eines Klangobjekts'. V: Musik und Verstehen. Aufsätze zur semiotischen Theorie, Ästhetik und Soziologie der musikalischen Rezeption, ur. isti in Hans-Peter Reinecke. Köln: Arno Volk Verlag in Hans Gerig 1973, 148-170. - Isti, ,Bedeutung, Struktur, Gegenfigur. Zur Theorie des musikalischen »Meinens«,. V: International Review of the Aesthetics and Sociology of Music 2/2 (1971), 213-229. - Isti, ,Musik und Zeichen. Aspekte einer nichtvorhandenen musikalischen Semiotik: V: Vladimir Karbusicky (ur.). Sinn und Bedeutung in der Musik. Darmstadt: Wissenschaftliche Buchgesellschaft 1990, 134-141. - Isti, ,Some non-communicative Aspects in Music'. V: International Review of the Aesthetics and Sociology of Music 5/1 (1974), 51-59.

Reinhard Schneider. Semiotik der Musik. München: Wilhelm Fink Verlag 1980, 241.

Prim. Vladimir Karbusicky. Grundriß der musikalischen Semantik. Darmstadt: Wissenschaftliche Buchgesellschaft 1986.
} 
tega močno vprašljiv tudi obstoj glasbenih pomenov. Rešitev se morda skriva prav v priznanju in povezovanju obeh možnosti, njunem harmoniziranju in kontekstualiziranju. Po tej logiki bi bilo mogoče, da del glasbe izkazuje znakovne kvalitete, del pa tudi ne, kar je morda povezano z različnimi načini funkcioniranja glasbenih pomenov, ali pa, da se zdi glasba v določenem zgodovinskem kontekstu bolj znakovno opredeljena in v drugem spet manj, odvisno pač od različnih historičnih faktorjev.

Natančnejši vpogled v teorije posameznih znanstvenikov pa nam pravzaprav lahko potrjuje misel, da se v sami sredici njihova razmišljanja niti ne razlikujejo drastično in da praktično vsi razkrivajo nekakšno dvojnost funkcioniranja povednosti glasbe. Tako že John Locke odkriva mentalne in zunanje znake, ${ }^{8}$ Roman Jakobson ločuje zunanjo in notranjo semiozo, pri čemer naj bi imele v glasbi dominantno vlogo glasbene enote same, ki se najprej nanašajo druga na drugo (notranja semioza), Wilson Coker pa vzpostavlja razliko med kongeneričnimi (en del skladbe je znak drugega) in ekstrageneričnimi glasbenimi pomeni. ${ }^{9}$ Razlikovanje med »notranjim«, imanentnim pomenom glasbe (njenih form, "struktur«) in "zunanjim" pomenom (zmožnost nanašanja na zunajglasbeno resničnost) odkriva tudi Etienne Gilson, ki ločuje med štirimi estetskimi doktrinami - imitacija, ekspresionizem, simbolizem in formalizem -, pri čemer prve tri vključujejo razumevanje glasbe kot imitacijske umetnosti, ki je zmožna referencialnih zvez, formalizem pa priznava zgolj imanentne glasbene pomene. ${ }^{10}$ Temu zelo podobna je sistematika Leonarda Meyerja, čigar razdelitev pa je mnogo bolj subtilna. ${ }^{11} \mathrm{~V}$ zgodovini razumevanja glasbe loči štiri skupine: za absolutiste obstaja glasbeni pomen samo v relacijah med glasbenimi elementi, prav tako se za formaliste notranji pomen razkriva le prek »igre form« (npr. E. Hanslick), vendar pa le-tem priznavajo tudi možnost emocionalnosti, za ekspresioniste leži izraz emocije sicer v glasbi sami, vendar pa ga je moč razložiti s pomočjo nanašanja na zunanji svet, referencialisti pa odkrivajo glasbene pomene le prek nanašanja na zunajglasbeni svet.

Podobne dvojnosti lahko odkrijemo tudi pri na začetku izpostavljenih raziskovalcih. Za glasbenega semiotika in teoretika topikov V. K. Agawuja so topiki »subjekti glasbenega diskurza«, ki "zagotavljajo okvir za diskusijo različnih tipov in nivojev asociacijske signifikacije v glasbi 18. stoletja. ${ }^{12}$ Gre torej za glasbene tvorbe, ki v določenem kulturnem kontekstu prevzemajo asociacijske, referencialne vezi z zunajglasbeno stvarnostjo in tako glasbi podeljujejo pomene. Agawu prevzema Saussurjev dvopolni koncept jezikovnega znaka in z njim definira topike kot značilne glasbene znake. Vendar pa Agawu odkriva, da poleg topičnih glasbenih znakov obstajajo tudi t.i. »čisti«, strukturalni znaki. „Čisti«, strukturalni znaki nimajo referencialnih vezi in podeljujejo glasbi sintaktični »občutek«. Agawu razvija Schenkerjevo teorijo, a jo aplicira na lokalni ravni. Za izhodišče vzame paradigmo začetek - sredina - konec: za vsako strukturalno enoto te paradigme namreč obstajajo značilne kompozicijske strategije, ki zaradi konvencionaliziranosti pridobivajo znakovne kvalitete. V glasbi po Agawuju torej delujejo znaki dveh vrst: topiki, ki so referencialni in tako izkazujejo zveze z zunajglasbenim svetom in strukturalni znaki, ki izhajajo iz paradigme

\footnotetext{
David Lidov. Elements of Semiotics. New York: St. Martin's Press 1999, 99.

Jean-Jacques Nattiez. Music and Discourse. Toward a Semiology of Music. New Yersey: Princeton University Press 1990, $107-114$.

Prim. prav tam.

Prim. L. B. Meyer. Emotion and Meaning in Music. Chicago: The University of Chicago Press $1956,1$.

V: K. Agawu, nav. delo, 19.
} 
začetek - sredina - konec in so nereferencialni, svoje "pomene " pa gradijo z znotrajglasbenim nanašanjem. V glasbi je tako vedno na delu nekakšna dialektika med »referencialno« površino in kontrapunktično-harmonskim, pretežno strukturalnim ozadjem. Vendar pa Agawu ne vzpostavlja antitetičnega odnosa med obemi vrstami znakov oz. semioz, temveč poudarja njuno soodvisnost. Glasbeno-semiotski proces tako zaznamuje interakcija med topičnimi in strukturalnimi znaki, le-ta pa se Agawuju razkriva v obliki »igre«.

Izrazito dvojnost lahko odkrijemo tudi v razmišljanjih Raymonda Monella, ki je skeptičen do glasbene referencialnosti, ${ }^{13}$ torej do možnosti, da bi glasbeni znaki oz. enote nekaj označevale. Glasba zanj ni referencialna, saj v procesu semioze ni mogoče odkriti objektov, na katere naj bi se nanašala. Glasba nima denotativnega pomena, saj "glasbenim terminom ne moremo pripisati "prvotnega pomena' «. ${ }^{14}$ Prave pomene generira v resnici struktura; glasba pridobi pomene šele v relacijah, ne v stvareh samih (denotatih). Tako se glasbeni pomeni ustvarjajo med glasbenimi strukturami samimi (npr. razmerje med motivom in njegovimi izpeljavami). Monelle pa po drugi strani vendarle ne poveličuje zgolj znotrajglasbenih pomenov glasbenih znakov in tako odpira paradoksalno dvojnost: glasba naj bi bila nereferencialna - nima denotativnih pomenov -, hkrati pa tudi ni avtonomna, saj je potrebno glasbene pomene poiskati in razložiti v »človeškem«svetu. Tako aporetično možnost dovoljuje Monellovo dojemanje glasbe kot alegorije; glasbena signifikacija sicer teče svobodno mimo vsake reference ali objekta, a kot alegorija dialogizira praktično s celotnim univerzumom pomena. ${ }^{15}$

Tudi Vladimir Karbusicky je prepričan, da je glasba nereferencialna, ker ne označuje objektnega sveta. Glasba je zanj nepojmovna, zvočni kompleksi pa nimajo označevalne funkcije. ${ }^{16}$ Vendar pa v procesu »sekundarne semantizacije« lahko pridobi pomene. Glasbenim elementom - "Zvočnim realijam« in ne glasbenim znakom - lahko pripišemo pomene v procesu semioze. Gre za proces nastajanja pomenov iz »nepojmovnih energij«. Kasneje se Karbusicky značilni teoretični polarnosti približuje s pomočjo delitve nemškega matematika in filozofa Gottloba Fregeja, ki loči med smislom in pomenom; pomen je povezal s čutno zaznanim predmetom, smisel pa z notranjo sliko, zaznamovano z občutji, ki so subjektivna in $s$ tem zelo različna. ${ }^{17}$ Karbusicky poudarja, da danes zaradi razvoja jezika oba pojma razumemo prav v obratnem pomenu - smisel se veže na »objektivno« konstrukcijo, medtem ko pomen na zunanjo predmetno realnost. Tudi glasbo je mogoče razumeti v luči tej dvojnosti: enkrat se zdi, da več pomeni (lahko odkrivamo zunanjo referencialnost), drugič da ima več smisla (spleta znotrajglasbene, imanentne vezi).

Najdlje je šel v tem smislu Jean-Jacques Nattiez, ki za razliko od mnogih teoretikov gleda z manj skepse na glasbeno referencialnost. Zanj je glasbeno delo simbolična forma, torej "znak ali zbir znakov, s katerim je povezan neskončen kompleks interpretantov. ${ }^{18}$ Interpretanti, ki jih vzbuja simbolična forma se dotikajo vseh treh ravni totalnega

\footnotetext{
3 Prim. Raymond Monelle. Linguistics and Semiotics. Edinburgh: Harwood Academic Publishers 1992.

Prav tam, 15.

5 Prav tam, 198.

16 Izjema so onomatopoije oz. "čiste« glasbene ikone, vendar gre tudi v primeru teh za prilagajanje kulturno pogojenim sistemom, kar je najjasneje razvdino iz pogostega obrazca "podobnost = identiteta , ki je pogosto "na delu « $v$ onomatopoijah (V. Karbusicky, nav. delo, 148).

17 Vladimir Karbusicky. 'Einleitung: Sinn und Bedetung in der Musik'. V: isti (ur.). Sinn und Bedeutung in der Musik. Darmstadt: Wissenschaftliche Buchgesellschaft 1990, 4.

18 J.-J. Nattiez, Music and Discourse. Toward a Semiology of Music, 8.
} 
glasbenega fakta (poietična, imanentna in estezična raven), česar pa se očitno niso zavedali raziskovalci pomenov v glasbi, saj so izmenično prisegali na nekakšno glasbi imanentno, strukturalistično semantiko (npr. zgodnji Monelle), spet drugič pa so prek analogij iskali pomene izven glasbe same (npr. Ratnerjeva toerija topikov ${ }^{19}$ ). Nattiez ne zavrača ne prvega ne drugega in ugotavlja, da je za zgodovino glasbe same kot tudi za raziskovanje njenih pomenov značilno menjavanje med poudarjanjem notranjega in zunanjega referiranja glasbe oz. "zunanjega" in "notranjega" pomena glasbe. Nattiez odpira prostor sobivanja »notranjega« in "zunanjega» referiranja.

Monellovo definiranje glasbe kot nereferencialne in neavtonomne, Jakobsonovo ločevanje med notranjo in zunanjo semiozo, Nattiezova ugotovitev o obstoju dve semioloških sistemov, ki sta zvezana z notranjim in zunanjim nanašanjem, dva tipa glasbenih znakov po Agawuju (topični in strukturalni) ter nenazadnje preseganje dihotomij z dvojnostjo med glasbenim pomenom in smislom, kakršno vpeljuje Karbusicky, nas utrjuje v spoznanju o dvojni naravi glasbene znakovnosti, pri čemer je delež enega ali drugega očitno močno odvisen od zgodovinskega trenutka in kulturne umeščenosti skladateljevega dela in poslušalčeve aktivnosti. ${ }^{20}$

To zadnje pa nam tudi že sugerira, da je potrebno problem znakovnosti glasbe očitno vpeti v širši kontekst, ki ga določa kopica različnih dejavnikov. Na to opozarja Monelle, ko vzpostavlja vezi med glasbenimi kodi in kodi drugih sfer. Take zveze naj bi bile kulturno pogojene, zaradi česar raziskovanje glasbenih pomenov takoj vključuje tudi širši kulturološki študij. ${ }^{21}$ Da je nujno upoštevati širše duhovnozgodovinske, kulturne in sociološke aspekte, poudarja tudi Faltin, ko prek Mukařovskega odpira široko referencialno polje s celoto socialnih pojavnosti, na katero naj bi se nanašali znaki umetnosti. "Avtonomni« glasbeni znak namreč artikulira socialno in kulturno pogojeno zavest ter različne aspekte določene kulture in družbe: pomen torej ni odvisen zgolj od denotata, temveč je prav tako rezultat socialno-kulturnega procesa. ${ }^{22}$ Kulturno in zgodovinsko odvisnost pa odkriva pri funkcioniranju topikov tudi Agawu. ${ }^{23}$ Zanj so topiki glasbene tvorbe, ki v specifično omejenem kulturnem in glasbenem kontekstu prevzemajo asociacijske, referencialne vezi z zunajglasbeno stvarnostjo in tako glasbi podeljujejo pomene. Gre pravzaprav za nekakšne kode, ki jih razumejo tako skladatelji kot poslušalci, vendar pa ta sposobnost njihovega razumevanja ni naravna, temveč pridobljena z učenjem in bivanjem v določenem zgodovinsko-kulturnem kontekstu.

Raziskovalci nas torej utrjujejo v spoznanju, da lahko zgodovinski in kulturni kontekst močno vplivata na spreminjanje glasbenih pomenov. Takšno zavedanje zgodovinske in kulturne pogojenosti glasbene semantike pa pred nas postavlja dva možna nivoja zgodovinskega spreminjanja povednosti glasbe:

19 Leonard G. Ratner. Classic Music. Expression, Form, and Style. New York: Schirmer Books 1980.

20 Tak dvojni model ponuja tudi Eero Tarasti, ki na glasbo prenaša nov lingvistični pojem: »dvojna artikulacija». Tako naj bi glasbeno komunikacijo determinirali dve različni strukturi: „Prva se manifestira v obliki, ki jo da skladatelj glasbeni substanci, poznani kulturi, medtem ko je druga v obliki, ki jo daje kultura individualni poslušalčevi izkušnji« (Eero Tarasti. $M y t h$ and $M u$ sic. Haag, Pariz, New York: Mouton Publishers 1979, 31). Pri dvojni artikulaciji si torej stojita nasproti skladateljev izraz na ravni tehničnega obrtništva in vsebina, ki jo ustvarja poslušalec na estetski ravni, pomembno pa je, da oba nivoja močno zaznamuje kultura: skladatelju zagotavlja substanco, ki jo potem oblikuje, hkrati pa vpliva na poslušalčevo interpretacijo dela.

21 Raymond Monelle. The Sense of Music. Princeton: Princeton University Press 2000, 228.

22 Peter Faltin. 'Die Bedeutung von Musik als Ergebnis sozio-kultureller Prozesse'. V: Die Musikforschung 26/4 (1973), 442.

23 Prim. K. Agawu, nav. delo. 
1. S časom se spreminja naše razumevanje glasbe - enkrat jo razumemo kot značilno semantično umetnost, drugič ji semantične kvalitete odrekamo. To je mogoče zasledovati v konstantnih premenah metodoloških paradigm. Če je 18. stoletje z retorično teorijo in naukom o afektih vzpostavilo trdne temelje za dojemanje povednosti glasbe, pa mnogi raziskovalci v 20. stoletju odkrivajo prav nezadostnost in zgrešenost analogij med jezikom in glasbo, zaradi česar glasbi odrekajo označevalno moč. Nenazadnje je mnoga glasbeno-semiotska oz. glasbeno-semantična raziskovalna neskladja mogoče razložiti prav z različnimi znanstveno-metodološkimi perspektivami, ki so se izredno hitro menjavale prav v preteklem stoletju; tako ostaja J.-J. Nattiez zavezan strukturalizmu, R. Monelle se od strukturalizma premika k postmodernistični dekonstrukciji, P. Faltin uporablja fenomenološko metodo, za V. Karbusickega je značilen antropološki pristop, E. Tarasti ${ }^{24}$ pa v svoji zadnjih delih prestopa med eksistencialiste.

2. V zgodovinskem toku se spreminja tudi kompozicijski metier, slogovne značilnosti in z njimi vred tudi pomembnost in delež glasbene povednosti. Skladatelji lahko tako v nekem obdobju svoje skladbe koncipirajo kot dela, ki bi jih bilo mogoče tolmačiti povsem znakovno, spet drugič pa se takemu pristopu odpovedujejo in celo zanikajo možnost glasbene "povednosti« ter vztrajajo pri imanentnosti glasbenih izrazil.

Gre seveda za spremembe na dveh različnih nivojih - v prvi točki zadevajo poslušalca, sprejemnika, našo recepcijo glasbe, v drugi pa samo glasbeno produkcijo, intencije skladatelja. Tako nas zgodovinsko-kulturni model spreminjajočega se deleža glasbene semantike vodi vsaj do štirih tipičnih semantično-asemantičnih situacij: na nivoju recepcije lahko prevladuje semantično dojemanje glasbenega toka, ali pa se le-to bolj kot ne umika sintaktično-imanetnemu dojemanju glasbene materialnosti, podobno pa lahko skladatelji glasbeni tok oblikujejo v izraziti želji po semantiziranju glasbenih elementov ali pa povsem nevtralno z osrediščanjem na glasbeno materijo samo. Iz tega bi bilo mogoče zaključiti, da se delež semantičnosti oz. asemantičnosti glasbe skozi zgodovino in verjetno tudi v različnih kulturah spreminja, da torej ni konstanten, nespremenljiv in zato kot tak ni ulovljiv v enostavno znanstveno paradigmo.
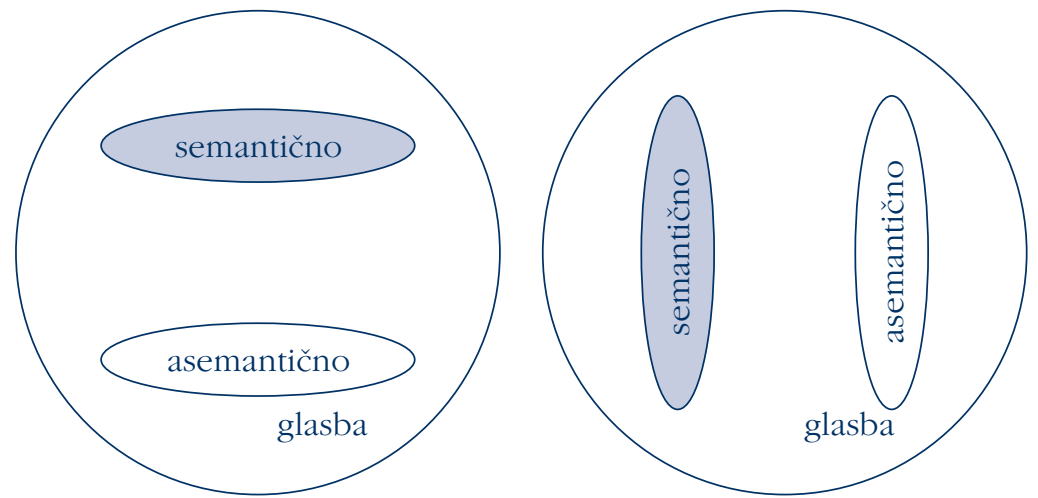

primer 1: spreminjujoči se delež semantičnosti in asemantičnosti glasbe iz perspektive glasbene produkcije (levo) in recepcije (desno)

24 Eero Tarasti. Existential Semiotics. Bloomington in Indianapolis: Indiana University Press 2000. 
Pri dejanskem poslušanju glasbe pride do križanja obeh perspektiv oz. modelov (gl. prim. 2). V takem križanju dveh različnih aspektov (semantičnost vs. asemantičnost) in dveh različnih nivojev (produkcija vs. recepcija) se izoblikujejo štiri možne kombinacije. Možno je, da se skladateljeve intencije in poslušalčev pristop (kompetenca) povsem prekrivajo (presečišči 1 in 4 v prim. 2), pri čemer lahko glasba obvelja kot popolnoma »semantična umetnost (npr. klasicistična glasba za Ratnerja in Agawuja) ali kot značilno »asemantična« (modernizem 20. stoletja za Kneifa), spregledati pa ne gre tudi variant (presečišči 2 in $3 \mathrm{v}$ prim. 2), v katerih si perspektivi producenta in sprejemnika stojita povsem vsaksebi. Če v prvem primeru lahko govorimo o adekvatnem razumevanju pa drugi razkriva delno nekompetenco poslušalca. Najpogostejši pa so seveda »vmesni« primeri delnega ujemanja oz. neujemanja semantičnih aspektov in nivojev (prostor med preseščišči v prim. 2).

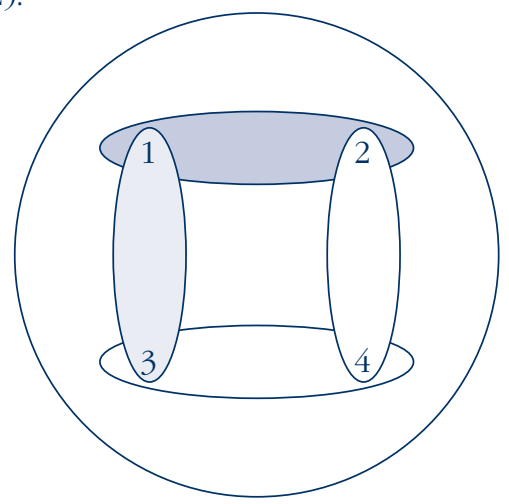

primer 2: križanje semantičnih perspektiv na ravni produkcije in recepcije: senčeni deli predstavljajo »semantične»deleže

S pomočjo takega modela, ki razkriva raznolikost križanja avtorjevih in sprejemnikovih perspektiv ter semantično-asemantičnih aspektov, je mogoče razložiti tudi spremenljivost dojemanja glasbe bolj oddaljenih zgodovinskih obdobij.

Pomudimo se v tej zvezi na kratko pri klasicistični glasbi Mozarta, Haydna in Beethovna, kakor jo razlagata L. G. Ratner in Agawu. Oba zagovarjata razumevanje s pomočjo topikov, torej izrazito znakoven, semiotski pristop. $\mathrm{V}$ ta namen skušata prek različnih zgodovinskih virov pokazati na utemeljenost asociacijskih povezav med določenimi glasbenimi strukturami in zunajglasbenimi fenomeni. Kako pa lahko na primer Mozartovo glasbo razume nekdo, ki mu vse te zveze med obredjem, literaturo, vedenjskimi vzorci in ceremonijam 18. stoletja in glasbenim strukturamo niso prezentne? Četudi se določenih modelov lahko nauči ob pogostem poslušanju ali ukvarjanju s klasicistično glasbo, pa mu vseeno ostaja zaprta izvorna pot signifikacije. Ali to pomeni, da tak, manj kompetenten poslušalec ne more estetsko uživati ob poslušanju klasicističnih del, ker jih pravzaprav ne dojema "pravilno«? Danes morda povprečen poslušalec ob na primer Mozartovem klavirskem koncertu celo bolj občuduje »asemantične« kvalitete te glasbe - navdušuje ga "pregledna« forma, »tekoč« harmonski stavek, ki vodi v značilni »ležerni allegro«, simetrija in periodična urejenost najmanjših glasbenih enot (dvotaktja, stavki, 
periode), iz harmonije izpeljana "enostavna« melodika, "prosojna« instrumentacija. V tem primeru lahko govorimo o očitni koliziji različnih aspektov in perspektiv dojemanja semantičnosti glasbe, pri čemer pa se je težko odločiti, katera izmed kombinacij je "prava" oz. edino sprejemljiva. Gotovo pa je, da mora Mozartova glasba za tako »asemantično« sprejemanje, ki je morda v primeru klasicistične glasbe res bolj značilno za laičnega poslušalca, vendarle ponuditi kak »asemantični« element in da jo je prav zato mogoče »brati« tako poudarjeno semiotsko kot tudi z izrazitim odklanjanjem iskanja zunajglasbenih, semantičnih povezav.

Glasba pa kljub bolj ali manj posrečenim »srečanjem« različnih semantičnih aspektov in perspektiv ostaja zvočno nespremenljiv fenomen - fizični dražljaj Mozartovega koncerta, ki ga poslušata strokovnjak za topičnost klasicistične glasbe in laik brez poznavanja asociacijskih vezi med klasicističnimi glasbenimi formulami in zunajglasbenimi fenomeni je v resnici enak. To pa pravzaprav potrjuje, da glasba ni enoznačno in primarno semantična, temveč da je njen »semantični«status močno odvisen od »zunanjih«, predvsem kulturno-zgodovinskih dejavnikov, ki bi jih lahko razumeli kot srečanje med semantičnima sistemoma skladatelja in poslušalca (gl. prim. 2).

Spoznanje, da lahko Mozartovo glasbo dojemamo enkrat semantično in drugič asemantično pa v resnici potrjuje tudi že prej izpostavljeno dvojno naravo povednosti glasbe - pri dvojnosti med semantičnim (zunanja referencialnost, asociacijske povezave s svetom življenja) in asemantičnim (prvenstvo imanentnih glasbenih zvez) imamo opravka pravzaprav z razliko med zunanjim in notranjim nanašanjem, če uporabimo Nattiezova termina.

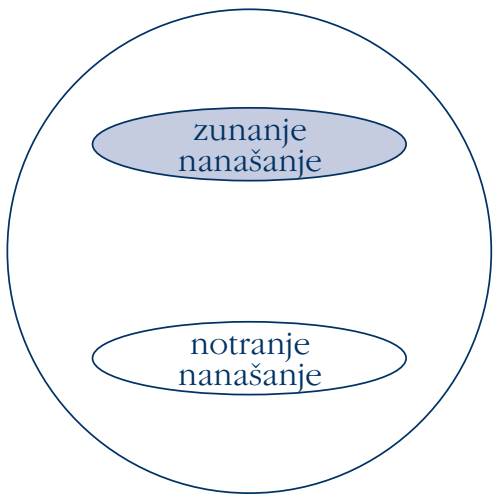

primer 3: semantičnost glasbe v odvisnosti dveh referencialnih sistemov: "zunanjega" in "notranjega"

Razlaganje pomenov glasbe s pomočjo dveh sistemov referencialnosti pa ukinja tudi osrednje metodološke napetosti, povezane z vprašanjem o glasbeni semantiki in/ali semiotiki. Oba sistema namreč pričata o znakovnosti glasbe, le da je pri zunanjem nanašanju lažje razkriti pomene takih "zunanjih« glasbenih znakov, "notranji« pomeni pa so močno zavezani glasbeni imanenci in s tem težje dostopni, predvsem glasbenemu laiku (na primer v obliki jezikovne verbalizacije). Tako bi lahko razliko med zunanjim in notranjim glasbe- 
nim nanašanjem razumeli ne samo v obliki polarnosti med semantičnim in asemantičnim, temveč tudi kot razmerje med semantičnim in semiotskim. Zunanje nanašanje je tesno sprepleteno s procesom označevanja, medtem ko je pri notranjem nanašanju to bistveno bolj zamegljeno - pri prvem se zdijo "pomeni« lažje dosegljivi, drug sistem pa razkriva svojsko znakovnost glasbe, ki se izčrpava predvsem v lastni kombinatoriki.

Seveda pa moramo biti pri takem ločevanju previdni: semantičnost in semiotičnost nekega pojava nista povsem ločeni kvaliteti, kot poudarja že Faltin. Pomeni - z njimi se ukvarja semantika - ne nastajajo brez znakovnosti, ki pa je predmet semiotike. Iz tega sledi, da je lahko glasba v celoti predmet semiotike, z njeno bolj ali manj izrazito povednostjo - ta je močno odvisna od zgodovinske in kulturne pogojenosti - pa se ukvarja semantika. Ta ugotovitev pa ni toliko pomembna zato, ker vzpostavlja metodološko razmerje med glasbeno semiotiko in semantiko, temveč bolj zaradi tega, ker jo lahko povežemo z mislijo, da je glasba v celoti sestavljena iz glasbenih struktur (za semiotika so to znaki), pri čemer nekatere hitreje in lažje spominjajo tudi na nekatere izvenglasbene strukture. Slednje so lažje opisljive, ker očitno obstaja homologija med izbrano glasbeno strukturo in strukturami drugih realnosti ali življenjskih izkušenj, ${ }^{25} \mathrm{ki}$ smo jim že podelili imena, jezikovne nalepke. Prav zaradi tega se zdi, da jih je možno verbalizirati, poimenovati in jim s tem dati povedne kvalitete.

Iz tega razloga bi bilo naše dvopolarne modele grafično bolje začrtati nekoliko drugače. Vsa glasba ima znakovne kvalitete, pri čemer pa je delež njene povednosti močno odvisen od kulturnih in zgodovinskih faktorjev, ki zadevajo tako avtorja dela kot njegovega poslušalca - vsa glasba je torej semiotska, spremenljiv je delež njene semantičnosti (tudi glasbene strukture, ki izkazujejo izrazito semantičnost, so prek znotrajglasbenih povezav oz. referenc povezane z drugimi glasbenimi enotami).

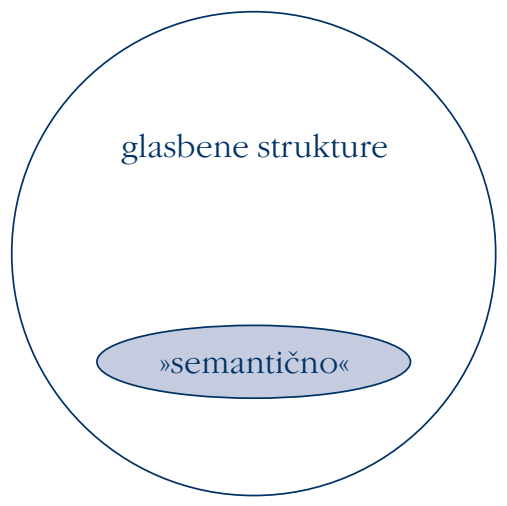

primer 4: glasbene strukture lahko v povezavi z različnimi semantičnimi sistemi prevzamejo večji ali manjši delež semantičnih kvalitet

Neka glasbena tvorba torej ni samo absolutno semantična ali asemantična in ne more imeti zgolj povedne ali zgolj kompozicijsko-tehnične funkcije. Vsaka struktura je

25 David Lidov. 'Technique and Signification in the Twelve-Tone Method'. V: The Sign in Music and Literature, ur. Wendy Steiner. Austin: University of Texas Press 1981, 196. 
v prvi vrsti glasbeno modelirana, je oblikovani glasbeni material, ki pa mu je mogoče pripisati zdaj bolj in drugič spet manj - odvisno od semantičnih nivojev in aspektov - povednosti. Razlog leži v dvojni naravi glasbenega nanašanja - notranjemu in zunanjemu referiranju. Tako glasbene enote spletajo vezi med seboj, kar pomeni, da določeno povednost lahko nosi glasbena sintaksa sama, na drugi strani pa lahko glasbene enote prinašajo asociacijske vezi z zunajglasbenim svetom in postajajo »opislije« po tej poti. Z zunanjo referencialnostjo pač zaznamujemo tiste glasbene tvorbe, katerih homološka ujemanja z zunanjim svetom se zdijo bolj odkrita in jasna, zaradi česar je omogočena lažja verbalizacija. Tako »odkrita« mesta bi lahko imeli za topike (L. G. Ratner, V. K. Agawu), lahko pa tudi za "semantične enklave«(T. Kneif) - gre pravzaprav za isti označbi za izrazito povedna, torej semantična mesta, le da obe pripadata različnim znanstvenim paradigmam.

Metodološko-epistemološke razlike v primeru vprašanja glasbene semiotike oz. semantike torej ne zrcalijo toliko nasprotij med »bojujočimi«se znanstvenimi perspektivami, kolikor so precej bolj verna odslikava dvojne, semiotsko-semantične narave glasbe. 